\title{
SIGNATURES OF ANTI-THOMSEN - FRIEDENREICH ANTIGEN ANTIBODY DIVERSITY IN COLON CANCER PATIENTS
}

\author{
O. Kurtenkov, M. Bubina, K. Klaamas* \\ Department of Oncology and Immunology, National Institute for Health Development, \\ Hiiu 42, Tallinn 11619, Estonia
}

\begin{abstract}
Aim: To determine whether the structural and functional diversities of naturally occurring antibodies to the Thomsen - Friedenreich (TF) antigen may be of diagnostic and prognostic value in colon cancer. Materials and Methods: Serum samples were taken from patients with colon cancer $(n=94)$ and healthy controls $(n=64)$. The level of TF-specific antibody isotypes and their sialylation were determined using ELISA and lectin-ELISA with synthetic TF-polyacrylamide conjugate as an antigen and a sialic acid-specific Sambucus nigra agglutinin (SNA). The avidity was determined using ammonium thiocyanate as a chaotrope. The accuracy of diagnostics was evaluated using the receiver operator characteristic curve analysis and the survival analysis employing the Kaplan - Meier method. Results: Compared to healthy controls, patients with colon cancer exhibited a lower level of anti-TF IgG antibodies, significantly lower ratios of TF-specific IgG/IgM and IgG/IgA, an increased SNA reactivity of anti-TF antibodies, mostly on account of IgG, and a lower avidity of TF-specific antibodies, especially their SNA-reactive subset. An increased SNA reactivity of anti-TF IgG was observed already at the early stages of cancer $(p=0.0004)$. The decrease of the ratio of IgG/IgM and IgG/IgA showed a good accuracy of diagnostics with about $60 \%$ sensitivity at $90 \%$ specificity. A similar potential was found for the SNA binding/IgG level index. The high level of TF-specific IgA antibodies was associated with a lower survival rate (hazard ratio $=0.34)$. Conclusion: This is the first report ever on the colon cancer-related signatures of anti-TF antibody diversity which show diagnostic potential, including in early cancer, and prognostic value. The hypersialylation of TF-specific antibodies appeared to be a common phenomenon in cancer. The signatures may be used as non-invasive antibody-based markers for colon cancer. Key Words: cancer biomarkers, colon cancer, Thomsen - Friedenreich (TF) antigen, anti-glycan antibody, antibody avidity, antibody glycosylation.
\end{abstract}

Alterations in cell surface glycosylation are often observed to take place in cancer cells, being involved in cancer cell adhesion, signaling, and invasion [1-3]. The overexpression of normally cryptic O-glycans is a permanent feature of cancers [4-6]. The Thomsen - Friedenreich antigen (Galß1-3GalNAc a-O-Ser/Thr) (TF, CD176) is an oncofetal mucin-type O-linked disaccharide which is overexpressed in tumor cells and is associated with tumor progression and metastasis [7-11]. Naturally occurring TF-specific antibodies of different isotypes are widely present in the circulation in health and disease [12, 13]. AntiTF antibody and TF-specific lectins have been shown to inhibit cancer cell proliferation and metastasis in TF expressing cells [14-16]. Clinically and experimentally observed prognostic improvements in cancer patients with a high level of TF-specific IgG antibodies indicate that the TF-specific innate and/or adaptive immune response is an important part of cancer immunosurveillance, and TF antigen is a promising target for cancer immunotherapy [17-22]. However, the clinical role of the diversity parameters of TF-specific antibodies, including glycosylation and functional activity, remains yet unclear.

Several recent studies showed that there were significant differences in the glycosylation profile of total human serum IgG between non-malignant controls and cancer patients [23-25]. Changes in the glycosyl-

Submitted: Junuary 31, 2018.

*Correspondence: E-mail: kerstiklaamas@gmail.com Abbreviations used: SNA - Sambucus nigra agglutinin; TF Thomsen - Friedenreich. ation pattern of antibodies to tumor-related antigens or other disease-specific glycans have been studied much less [26-28]. We recently showed that naturally occurring anti-TF antibodies were very heterogeneous in terms of sialylation and avidity. Moreover, some alterations in this diversity revealed diagnostic and prognostic values for gastric cancer [29, 30].

Colorectal cancer is one of the most common malignancies in both males and females and the second leading cause of cancer death in Western countries [31]. Unfortunately, the majority of the current serological markers (including autoantibody-based) show a low diagnostic accuracy in the early stages of cancer [32-36].

The primary objective of this study was to confirm the idea that the signatures of naturally occurring TF-specific antibody such as the level and proportions of different antibody isotypes, their sialylation pattern and avidity may be of clinical importance for colon cancer diagnostics, staging, and prognostics. Our previous and present findings show that some changes in TF-specific antibody signatures appear to be a common feature for at least two types of cancer (gastric, colon) and can be promising in cancer diagnostics, including the early stages of the disease, and prognosis.

\section{MATERIAL AND METHODS}

Subjects. Serum samples were taken from healthy blood donors and individuals with histologically verified colon carcinoma (Table 1). The investigation was carried out in accordance with the ICH GCP Standards and approved by Tallinn Medical Research Ethics Com- 
mittee, Estonia. A written informed consent was obtained from each subject under study. Tumor staging and morphology were based on the histopathological (pTNM) classification of malignant tumors. The serum samples were stored in aliquots at $-20^{\circ} \mathrm{C}$ until use.

Table 1. The characteristics of groups under investigation

\begin{tabular}{lcccc}
\hline \multicolumn{1}{c}{ Group } & $\mathrm{n}$ & Male & Female & $\begin{array}{c}\text { Median age (range), } \\
\text { years }\end{array}$ \\
\hline Donors & 64 & 25 & 39 & $50(24-78)$ \\
Colon cancer patients & 95 & 43 & 52 & $65(34-85)$ \\
Stage I & 21 & 8 & 13 & $70(37-80)$ \\
Stage II & 25 & 11 & 14 & $71(57-85)$ \\
Stage III & 24 & 12 & 12 & $70(46-84)$ \\
Stage IV & 25 & 12 & 13 & $64(34-79)$ \\
\hline
\end{tabular}

TF-specific antibody assay. The levels of anti-TF IgG, IgM and IgA were determined by the enzyme-linked immunosorbent assay (ELISA). The plates (NUNC Maxisorp, Denmark) were coated with a synthetic TF-polyacrylamide conjugate (TFPAA, Lectinity, Russia; 10 mol\% of carbohydrate) in the carbonate buffer, $\mathrm{pH}$ 9.6. After the overnight incubation, triple washing and blocking with a Superblock solution (Pierce, USA) for $30 \mathrm{~min}$ at $25^{\circ} \mathrm{C}$, the serum samples diluted $1: 25$ in PBS-0.05\% Tween (Tw) were applied for $1.5 \mathrm{~h}$ at $25^{\circ} \mathrm{C}$. After the subsequent washing with PBS-Tw, the level of bound anti-TF antibodies was determined using the alkaline phosphatase conjugated goat antihuman IgG, IgM (Sigma, USA) or IgA (Dako, USA) and $p$-nitrophenylphosphate disodium hexahydrate (pNPP, Sigma, USA). The absorbance values were read at $405 \mathrm{~nm}$ (Tecan Reader, Austria). The optical density value (O.D.) of control wells (blank: the Superblock solution instead of serum) was subtracted from that of antibody-coated wells and each sample was analysed in duplicate. To standardize the assay, standard serum (A) was included in each plate for IgG determination and lectin binding measurement. The interassay variations were minimized by using the correction factor $(\mathrm{CF})$ :

$C F=1 /($ standard serum A values - blank) $\times 100$.

The results were expressed in relative units $(R U)$ : $\mathrm{RU}=$ sample O.D. value $\times \mathrm{CF}$.

SNA lectin reactivity of TF-specific antibodies. The lectin reactivity of TF glycotope-specific antibodies was measured in a similar way, except that the binding of the neuraminic acid (sialic acid) -specific Sambucus nigra agglutinin (SNA) to the absorbed antiTF antibodies was determined. The biotinylated SNA (Vector Laboratories, Inc., USA) in $10 \mathrm{mmol} / \mathrm{I}$ Hepes, $0.15 \mathrm{~mol} / \mathrm{I} \mathrm{NaCl}, 0.1 \mathrm{mmol} / \mathrm{I} \mathrm{CaCl}_{2}, \mathrm{pH} 7.5$ was applied at a concentration of $5 \mu \mathrm{g} / \mathrm{ml}$ for $1.5 \mathrm{~h}$ at $25^{\circ} \mathrm{C}$. The bound lectin was detected with a streptavidin-alkaline phosphatase conjugate (Dako, USA) and pNPP (Sigma, USA). The O.D. of control wells (no serum sample) was subtracted from that of antibody-coated wells to determine the lectin binding. Each sample was analysed in duplicate. The value of the SNA binding to all TF-specific antibodies and the ratio of SNA binding to TF-specific lgG, IgM and IgA (SNA/Ig index) were determined.
Avidity of TF-specific antibodies. The avidity of anti-TF IgG, IgM, or a pool of IgG+lgM+lgA antibodies was determined by ELISA. The plates were coated with the synthetic TF-polyacrylamide conjugate in the carbonate buffer, pH 9.6, $5 \mu \mathrm{g}$ per well. After the overnight incubation at $+4{ }^{\circ} \mathrm{C}$, washing with PBS $-0.05 \%$ Tw and blocking with the Superblock solution as above, the serum (diluted 1:25 in PBS - 0.05\% Tw) was applied for $1.5 \mathrm{~h}$ at $25^{\circ} \mathrm{C}$. After subsequent washing ammonium thiocyanate $\left(\mathrm{NH}_{4} \mathrm{SCN}\right)$ as a dissociating agent was added at a concentration of $1.25 \mathrm{~mol} / \mathrm{l}$ for $15 \mathrm{~min}$ at $+25^{\circ} \mathrm{C}$. The bound antibodies were detected with the alkaline phosphatase conjugated goat anti-human $\lg G$, IgM or anti-( $\lg G+\lg M+\lg A) \lg s$, and pNPP. The absorbance values were read at $405 \mathrm{~nm}$. The relative avidity index was calculated for each sample and expressed as the percentage of reactivity remaining in the thiocyanate-treated wells in relation to that of untreated wells (PBS-Tw instead of chaotrope).

Avidity of SNA-reactive anti-TF antibodies. The avidity of SNA-reactive anti-TF antibodies (a pool of all isotypes) was determined by ELISA in a similar way. The plates (NUNC Maxisorp, Denmark) were coated with the synthetic TF-polyacrylamide conjugate as above. After the overnight incubation at $+4^{\circ} \mathrm{C}$, triple washing and blocking with the Superblock solution for $30 \mathrm{~min}$ at $25^{\circ} \mathrm{C}$, the serum samples (diluted $1: 25$ in PBS- $0.05 \%$ Tw) were applied for $1.5 \mathrm{~h}$ at $25^{\circ} \mathrm{C}$. After subsequent washing ammonium thiocyanate $\left(\mathrm{NH}_{4} \mathrm{SCN}\right)$ as a dissociating agent was added at a concentration of $1.25 \mathrm{~mol} / \mathrm{l}$ for $15 \mathrm{~min}$ at $+25^{\circ} \mathrm{C}$. To detect the lectin reactive antibodies, the biotinylated SNA (Vector Laboratories, Inc., USA) in $10 \mathrm{mmol} / \mathrm{l} \mathrm{Hepes,} 0.15 \mathrm{~mol} / \mathrm{I} \mathrm{NaCl}$, $0.1 \mathrm{mmol} / \mathrm{I} \mathrm{CaCl}_{2}$, and at $\mathrm{pH} 7.5$ was applied at a concentration of $5 \mu \mathrm{g} / \mathrm{ml}$ for $1.5 \mathrm{~h}$ at $25^{\circ} \mathrm{C}$. The bound lectin was detected with a streptavidin-alkaline phosphatase conjugate and pNPP. The proportion of TF-specific antibody SNA reactivity remaining after treatment with chaotrope was defined as the avidity index of SNA reactive anti-TF antibodies.

Statistical analysis. The results were analysed using the nonparametric Mann - Whitney $U$ test or Student's T-test, where appropriate, and the Pearson two-tailed correlation. Survival analysis was carried out by the Kaplan - Meier method, employing the Estonian Cancer Registry database. The median of the parameters was used as cut-off. The receiver operator characteristic (ROC) curve analysis was used to evaluate the sensitivity and specificity of changes found in colon cancer patients, as well as the accuracy of diagnostics. The respective difference between the groups was considered to be significant when $p \leqslant 0.05$. All calculations were performed using the GraphPad Prism 5 and SPSS 15.0 software.

\section{RESULTS}

Anti-TF IgG, IgM and IgA antibody levels. Among the three Ig isotypes tested, the level of TF-specific IgG antibodies was found to be significantly lower in cancer patients compared with controls $(p=0.013)$. Notably, 
this decrease was mostly observed in patients with early cancer ( $p=0.0005$ in stage I patients) (Fig. 1,a). Neither significant changes in the level of IgM and IgA anti-TF antibodies (Fig. 1, $b, \mathrm{c}$ ) nor appreciable interindividual variations in the levels of these isotypes were observed at any stage of the disease. The level of IgM and IgA was about twice higher than that of IgG antiTF antibodies in patients with any stage of the disease.
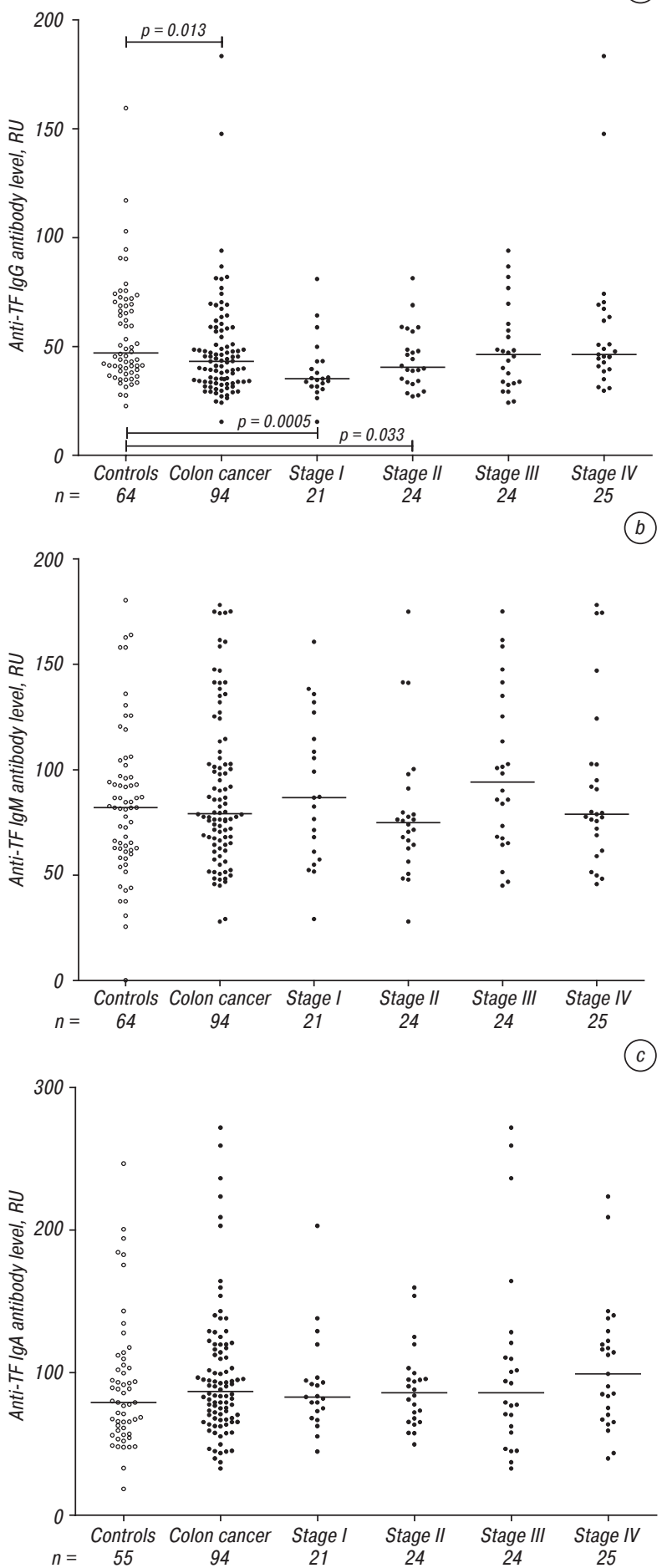

Fig. 1. The anti-TF antibody level in controls and cancer patients by disease stage. Anti-TF IgG (a), anti-TF IgM $(b)$ and anti-TF IgA $(c)$ antibody level. Each dot represents one single individual and horizontal lines denote group median. $p$-values were calculated using the Mann - Whitney $U$ test and are shown for comparison
In donors, a positive correlation between the levels of anti-TF IgG and IgM ( $r=0.27 ; p=0.0295)$ was established, while in cancer patients, the trend towards a negative correlation $(r=-0.177 ; p=0.087)$ was observed (Fig. 2).

A more pronounced difference in IgG and IgA level interrelations between the patients and controls was revealed, i.e. no correlation in donors $(r=-0.033$; $p=0.8)$ was observed but there was found a significant negative correlation in cancer patients $(r=-0.34$; $p=0.0007)$. In addition, a positive correlation between the levels of IgA and IgM level was observed only in the cancer group $(r=0.31 ; p=0.0024)$. Compared with controls, a significantly lower ratio of $\lg G$ to $\lg M(p=0.0037)$ and $\lg G$ to $\lg A(p=0.004)$ was observed in cancer patients, especially in those with early (stage I) cancer (Fig. 3, $a, b$ ). The IgM/IgA ratio was similar in patients and controls $(p=0.96)$ (Fig. 3, $c$ ). Thus, the decrease of anti-TF IgG level as well as changes in the relative proportion of different TF-specific antibody isotypes were characteristic of patients with colon cancer.

SNA reactivity of TF antibodies. A pool of all antiTF antibody isotypes showed a significantly higher SNA reactivity in cancer patients compared with controls $(p=0.004)$. This increase in SNA binding was observed mostly in patients with the advanced stages of cancer unlike donors $(p<0.0001)$ or patients with the early stages of the disease ( $p=0.0006)$ (Fig. 4).

A significantly higher SNA/lgG index was observed in cancer patients $(p<0.0001$ for the whole cancer group) irrespective of cancer stage (Fig. 5), being significantly higher already in stage I patients $(p=0.0013)$. The SNA/IgM and SNA/IgA indexes showed a similar trend: $p=0.066$ and $p=0.077$, respectively (see Fig. 5). Thus, the increased SNA reactivity of TFspecific antibodies observed in patients with colon cancer was mostly related to the IgG isotype.

Avidity of anti-TF antibodies in colon cancer patients and controls. A significantly lower avidity of TF-specific antibodies (a pool of all isotypes) was found in colon cancer patients compared with controls $(p=0.05)$. This decrease was associated with all three Ig isotypes ( $p=0.07,0.06$ and 0.11 for IgG, IgM and IgA, respectively) (Fig. 6). A significantly lower avidity of TF-specific antibodies (a pool of all isotypes) and IgA was observed at all stages of cancer. IgG antibodies exhibited the highest avidity followed by IgA and IgM isotypes. A positive correlation between the avidity of $\lg \mathrm{M}$ and $\lg \mathrm{A}$ antibodies was revealed in both colon cancer patients and controls $(r=0.49$ and 0.35 , respectively; $p<0.005$ ), but not between the avidity of $\lg M$ or $\lg A$ and $\lg G$ isotypes $(r=0.09-0.23$; $p=0.37-0.19$ ).

The SNA-reactive anti-TF antibodies (all isotypes) also showed a significantly lower avidity in cancer patients $(p=0.015)$ irrespective of cancer stage (Fig. 7), including patients with early (stage I) cancer $(p=0.045)$; for stage I $+\| p=0.028$ and for stage III + IV $p=0.032$. The SNA-reactive anti-TF an- 

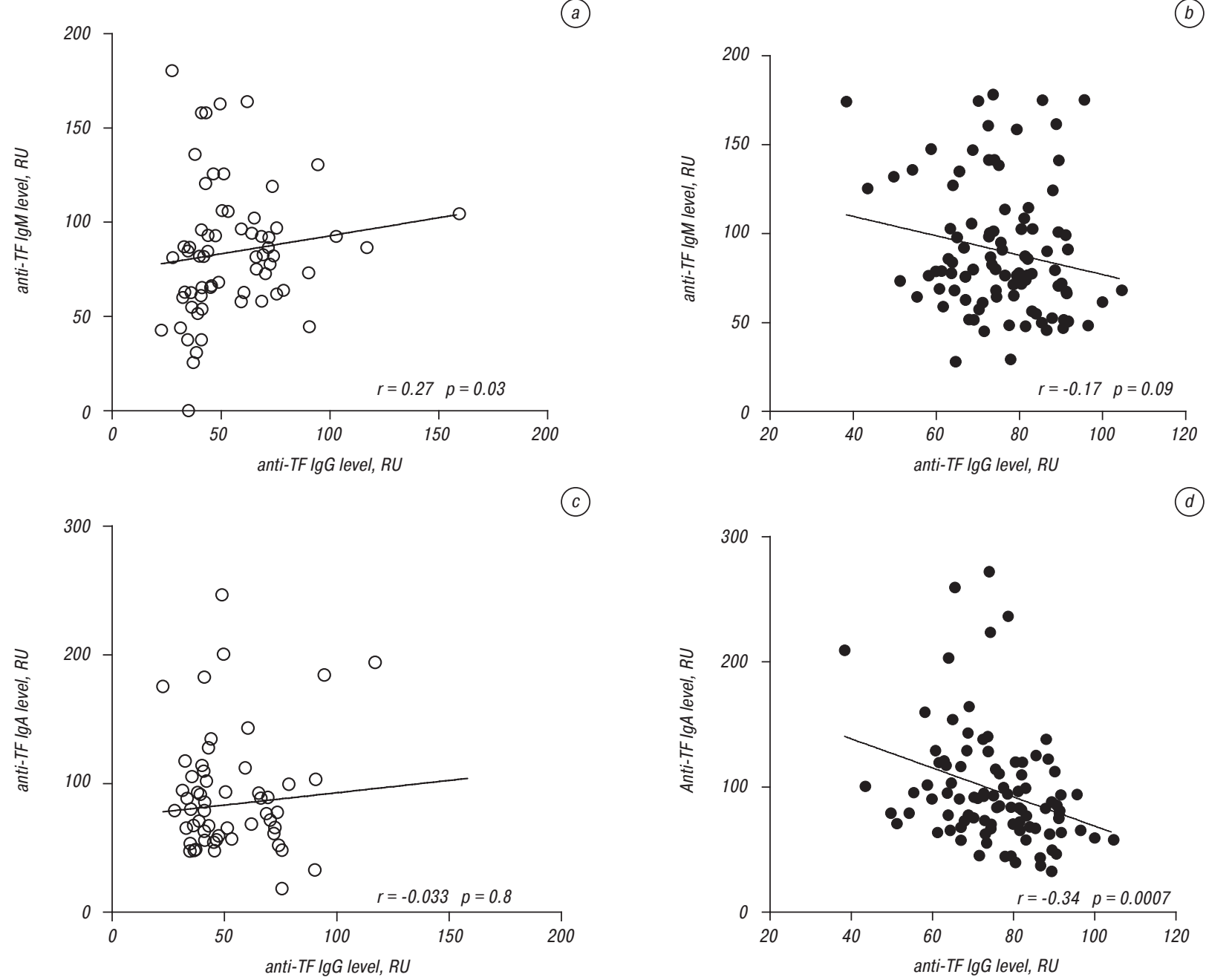

Fig. 2. Correlation between the levels of different isotypes of anti-TF antibodies. The correlation between IgG and IgM in controls (a) and in cancer patients $(b)$. The correlation between $\lg G$ and $\lg A$ in controls $(c)$ and cancer patients $(d)$

tibodies demonstrated a much lower avidity than the whole population of TF-specific antibodies (see Fig. 7) in both cancer patients $(p=0.0001)$ and controls $(p<0.0001)$. Interestingly, there was observed a positive correlation between the avidity of SNA-positive antibodies and the SNA binding values only in patients with cancer $(r=0.33 ; p=0.0012)$ but not in controls $(r=0.11 ; p=0.54)$, whereas the avidity of all anti-TF antibodies pool showed a trend towards a negative correlation in cancer patients $(r=-0.18 ; p=0.18)$. Thus, in patients with colon cancer the avidity of anti-TF antibodies was lower already in the early stages of the disease. These changes were more associated with the SNA-reactive population of TF-specific antibodies.

Diagnostic potential. Using the ROC curve statistics, the more pronounced cancer-related changes in IgG/lgM ratio, SNA binding value, SNA/IgG index, and avidity of SNA-reactive anti-TF antibodies were considered as possible cancer biomarkers (Table 2).

The decrease of the $\mathrm{lgG} / \mathrm{lgM}$ ratio in cancer showed a rather good diagnostic accuracy especially in early (stage I) colon cancer patients (Fig. 8, a): area under the curve $(A \cup C)=0.7566$; sensitivity $69.84 \%$ and specificity $76.19 \%$; the sensitivity at $90 \%$ specificity was equal to $60.3 \%$. The $\lg G / \lg A$ ratio showed a similar, slightly lower result (Fig. $8, b$ ). In advanced cancer the respective difference between patients and controls was much less significant (see Table 2).

The SNA binding values showed a rather low discrimination ability: $A \cup C=0.642$, the sensitivity was only $21 \%$ at $90 \%$ specificity. The SNA reactivity of anti-TF IgG defined as the SNA/IgG index also displayed a moderate sensitivity in early (stage I) cancer: AUC $=0.74$, sensitivity $65.45 \%$ and specificity $71.43 \%$ (Fig. 8, c), while at the advanced stages of cancer the respective values were slightly lower (see Table 2). The values of the sensitivity of the SNA/lgA index as well as the SNA-positive antibody avidity were in the range of $47-65 \%$ at a specificity of $63-73 \%$ (see Table 2 ).

Thus the relative proportion of anti-TF antibody isotypes and their SNA reactivity may be used as serological biomarkers for colon cancer. Notably, for the $\mathrm{IgG} / \mathrm{IgM}$ ratio the highest sensitivity and specificity values were obtained just in patients with early (stage I) cancer.

Relation to survival. The survival rate of patients a with high level of anti-TF antibodies (a pool of all isotypes) was found to be worse mostly on account of stage III patients (Fig. 9, $a, b$ ). A better survival was observed only in patients with stage I and II having a higher level of anti-TF IgG (HR $=1.62,95 \%$ Cl $0.65-4.03, p=0.229$ ) (Fig. 9, $c$ ). In contrast, the 

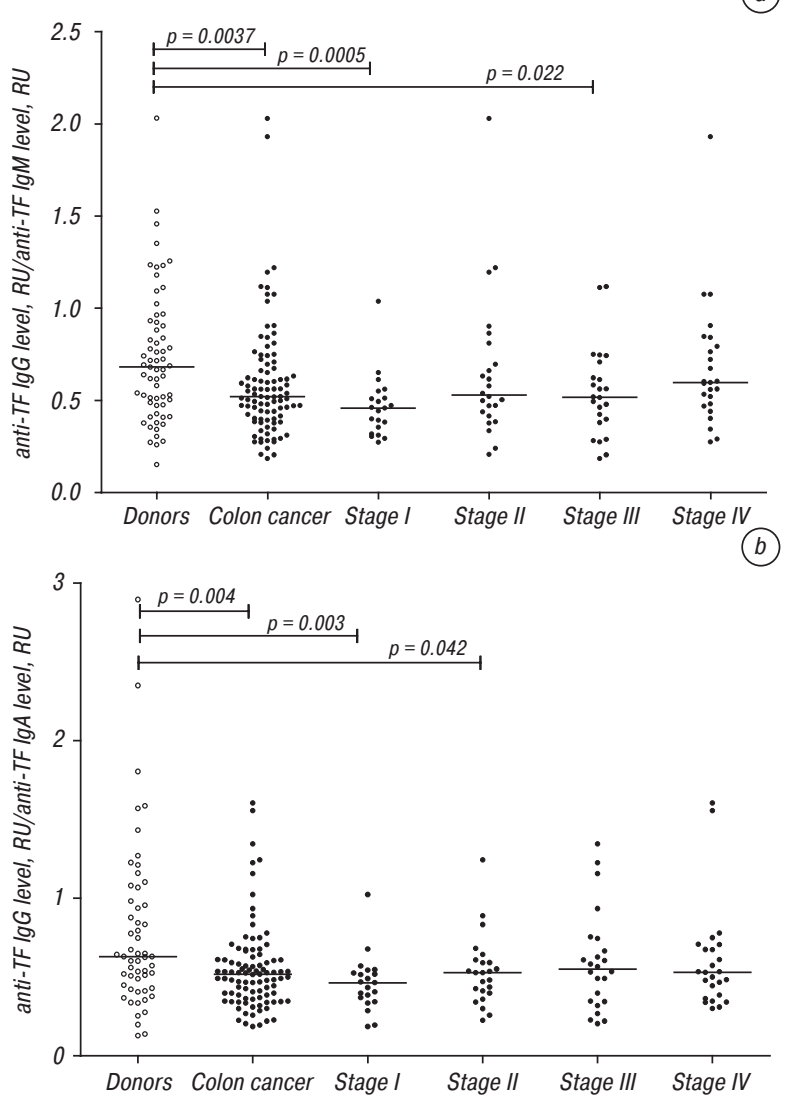

(c)

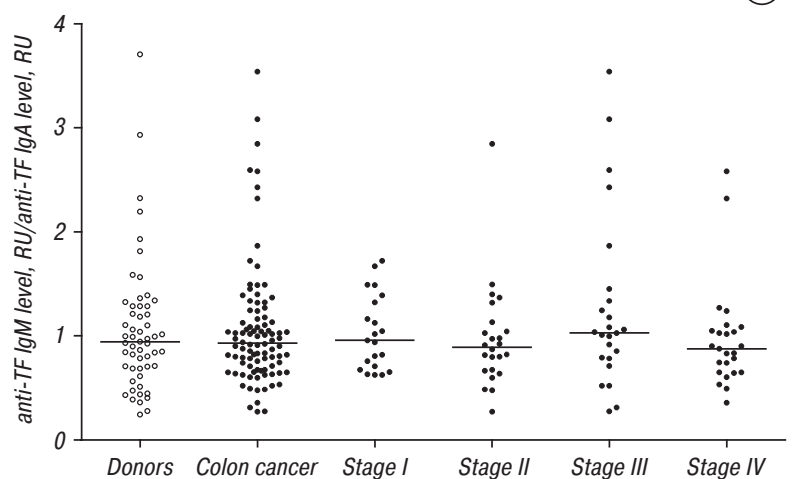

Fig. 3. The ratio of anti-TF IgG to anti-TF IgM and IgM to $\lg A$ in controls and cancer patients by disease stage: $a-\lg / \lg M$; $b-\lg \mathrm{G} / \lg \mathrm{A} ; c-\lg \mathrm{M} / \lg \mathrm{A}$

high level of TF-specific IgA antibodies in cancer patients was associated with a worse survival rate $(\mathrm{HR}=0.59 ; p=0.068)$ mostly in stage Il cancer patients $(\mathrm{HR}=0.34,95 \% \mathrm{Cl} 0.11-1.04 ; p=0.059)($ Fig. 9, $d, e)$. The level of anti-TF IgM was not related to the overall survival ( $p=0.71$ ), with a slight trend towards a better survival of stage III cancer patients having a high level of TF-specific $\lg \mathrm{M}(\mathrm{HR}=2.42,95 \% \mathrm{Cl} 0.63-9.3$; $p=0.19$ ).

Early-stage cancer patients (I + II) with a high IgG/ IgM ratio revealed a better survival $(\mathrm{HR}=2.27,95 \%$ Cl $0.91-5.63 ; p=0.077$ ) whereas patients with stage III cancer showed a lower survival rate $(\mathrm{HR}=0.33,95 \%$ Cl 0.09-1.16; $p=0.085$ ) (Fig. 9, $f, g$ ). There was observed a very similar association of survival with $\lg \mathrm{A} /$ IgM ratio: stage I cancer patients ( $\mathrm{HR}=1.88,95 \%$ Cl 0.37-9.64) displayed a trend towards a better sur-

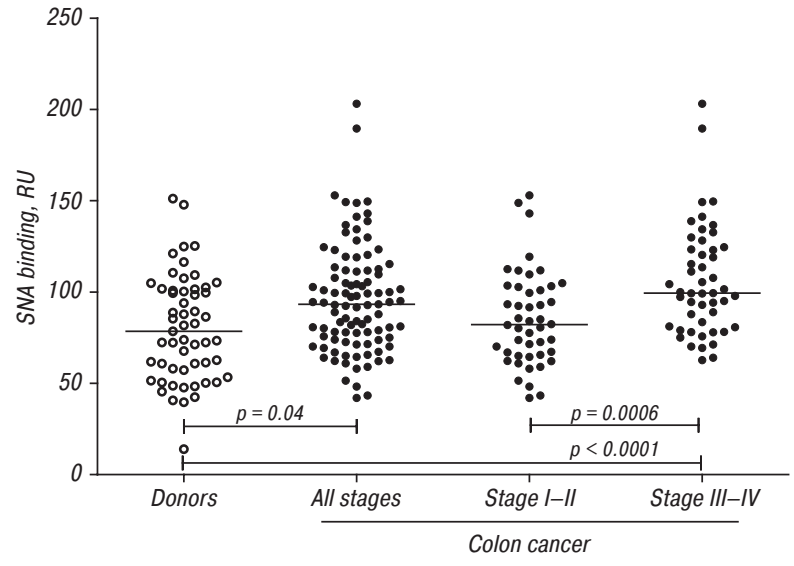

Fig. 4. The SNA-reactivity of TF specific antibodies (a pool of all isotypes) in cancer patients and controls

vival in contrast to those with stage III cancer whose survival was worse $(\mathrm{HR}=0.25,95 \% \mathrm{Cl} 0.06-0.96$; $p=0.044)($ Fig. 9, $g, h)$.

The level of SNA binding to a pool of all anti-TF antibody isotypes, as well as the SNA/lgA index, showed no association with overall survival $(p=0.32)$. However, the higher SNA/lgG index was associated with a trend towards a better survival $(\mathrm{HR}=1.51,95 \% \mathrm{Cl} 0.87-2.61$; $p=0.14$ ) whereas patients with a high SNA/IgM index demonstrated a low survival rate (Fig. 9, $h, i$ ) especially in early (stage I) cancer (HR $=0.159,95 \%$ Cl $0.027-0.94 ; p=0.042$ ). No significant association of anti-TF antibody avidity with the overall and stagedependent survival was revealed for a pool of all antibody isotypes $(p=0.20)$ as well as for the avidity of IgG and IgA. Interestingly, stage I-II cancer patients with a higher avidity of SNA-reactive anti-TF antibodies exhibited a significantly lower survival rate (Fig. 9, $j$ ) whereas patients with advanced cancer (stage III + IV) demonstrated a slightly opposite trend towards a better survival, or no association with survival (stage IV).

Based on the above results, the relative proportion of different TF-specific antibody isotypes as well as SNA/IgG index showed a better prognostic potential than antibody levels per se.

\section{DISCUSSION}

In the past decade, an essential role of glycans in the tuning of cellular and humoral immunity has been established [37-39]. Having altered post-translational modifications and/or aberrantly expressed, tumorassociated glycans can trigger an immune response $[1,2,10,33]$. Naturally occurring antibodies to tumorassociated glycans, including the TF glycotope, were shown to participate in antibodies-mediated tumor defence, and their level was associated with tumor progression, metastases, and patients survival [7, 8, 18-20]. A common trend towards the decrease of the level of natural anti-TF antibody in serum was found in cancer patients [12, 13, 41]. We suggest that it is more likely related to the elimination of pre-existent natural antibodies after their interaction with circulating tumor- or host-derived TF-positive ligands or, due to the accumulation of natural anti-TF antibodies in the tumor microenvironment with subsequent modifica- 

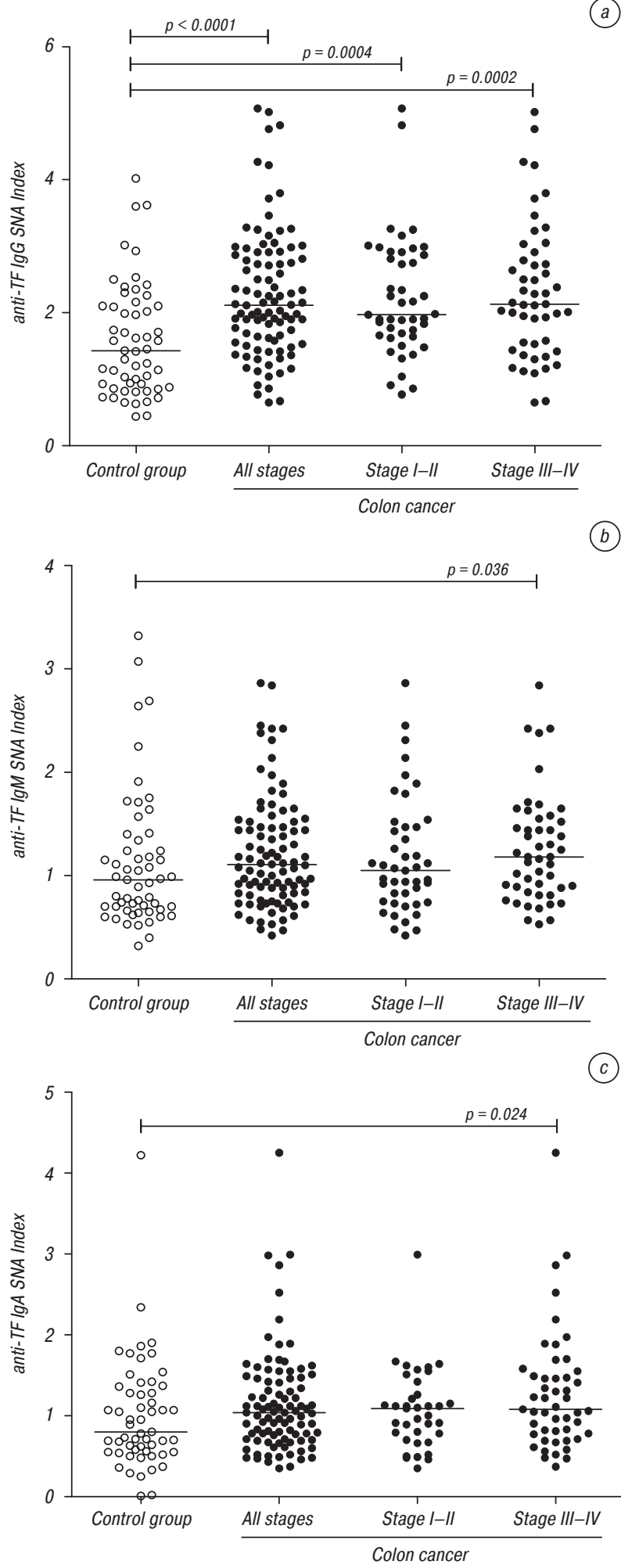

Fig. 5. The ratio of SNA binding value to anti-TF antibody isotypes level (SNA index) for different isotypes of TF-specific antibodies by cancer stage: $a-\mathrm{SNA} / \mathrm{IgG}$ index; $b-\mathrm{SNA} / \mathrm{IgM}$ index; $c$ - SNA/ IgA index

tions, including alteration of their glycosylation profile. In any case, this implies that no appreciable adaptive immune response to the TF glycotope was observed in cancer patients.

Based on our previous studies on patients with gastric cancer [27-30], we assumed that the diversity parameters of TF-specific antibodies, such as level

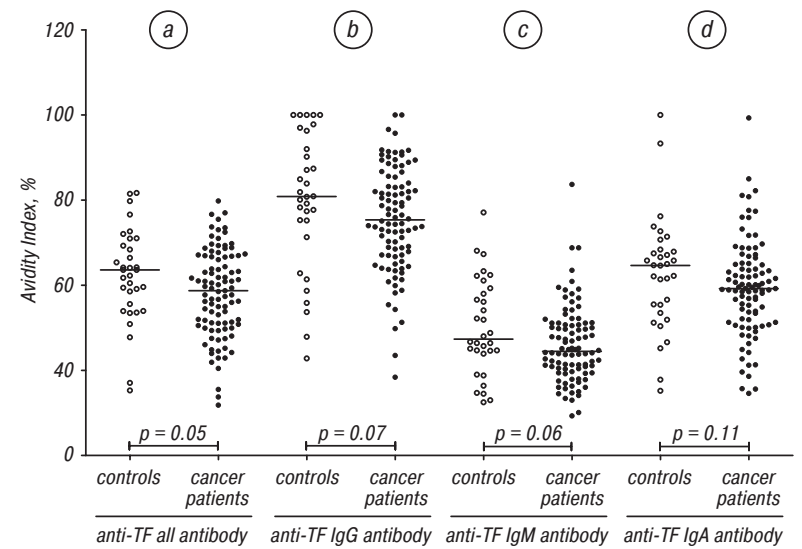

Fig. 6. Avidity of TF-specific antibodies in cancer patients and controls: $a-$ a pool of all anti-TF antibody isotypes; $b-\operatorname{lgG}$; $c-\lg \mathrm{M} ; d-\lg \mathrm{A}$

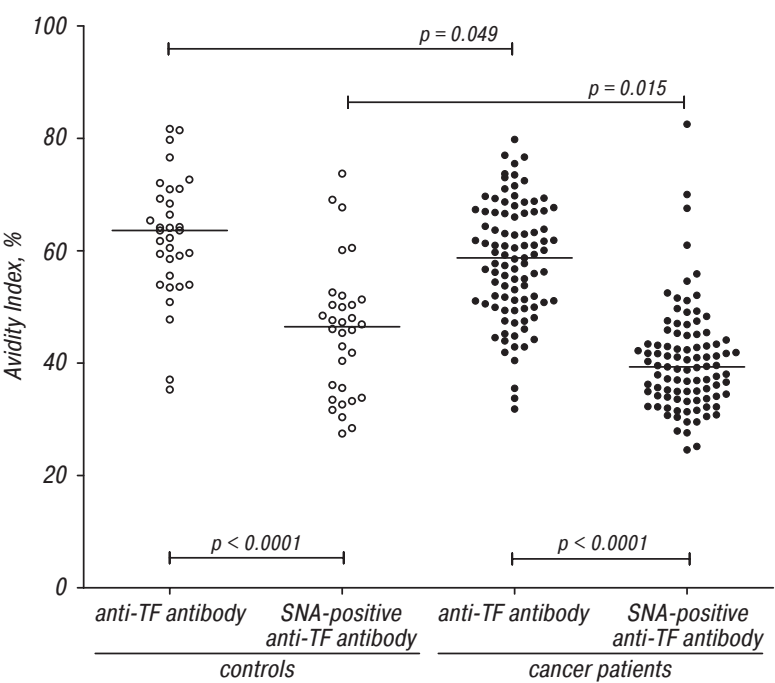

Fig. 7. Comparison of the avidities of total anti-TF antibodies and SNA-positive TF-specific antibodies in controls and colon cancer patients. $p$-values are shown for comparison

in serum, isotypes profile, glycosylation (sialylation) and avidity, might be used as serological biomarkers for colon cancer as well. In addition, an attempt to find the integral criteria of clinical importance based on interrelations between the parameters studied was undertaken.

In the present study, we showed that TF-specific antibodies were very heterogeneous in terms of isotypes profile, sialylation, avidity, and relation to survival. Besides, changes of some parameters, such as $\operatorname{lgG} / \operatorname{lgM}$ and $\lg A / \lg M$ ratios and SNA/IgG index, revealed a good diagnostic accuracy at the early stages of colon cancer and can be used as novel diagnostic biomarkers. The anti-TF IgG level was associated with a better survival, which was in accordance with previously reported findings in patients with gastrointestinal or breast cancer [18-20, 40-42]. In order to establish whether the relative proportions of different anti-TF antibody isotypes have diagnostic and/or prognostic value, we attempted to establish the ratio between the levels of TF-specific $\lg G$, IgM and IgA antibodies at different stages of colon cancer. The ratios of IgG/ $\lg M$ and $\lg G / \lg A$ were found to be lower at all stages of the disease, but the association of $\lg G / \operatorname{lgM}$ with 
(a)

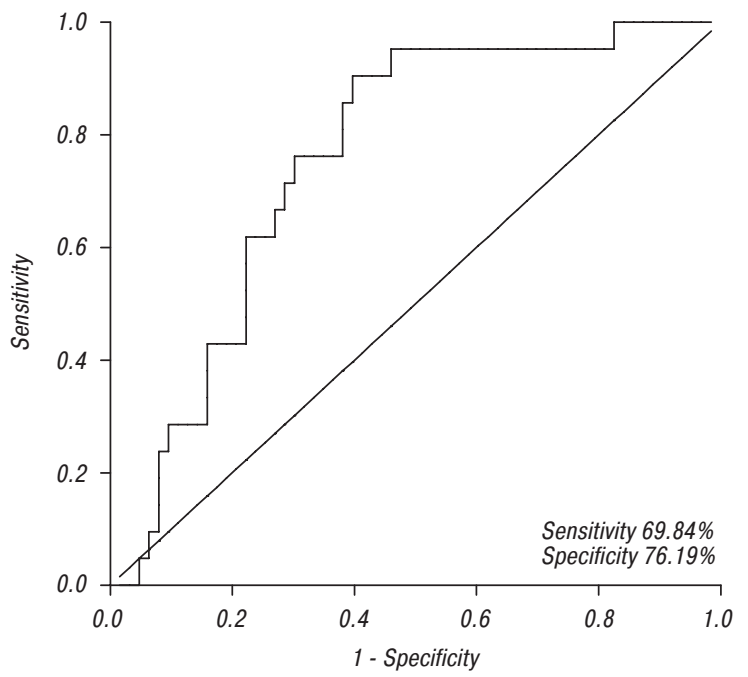

(b)

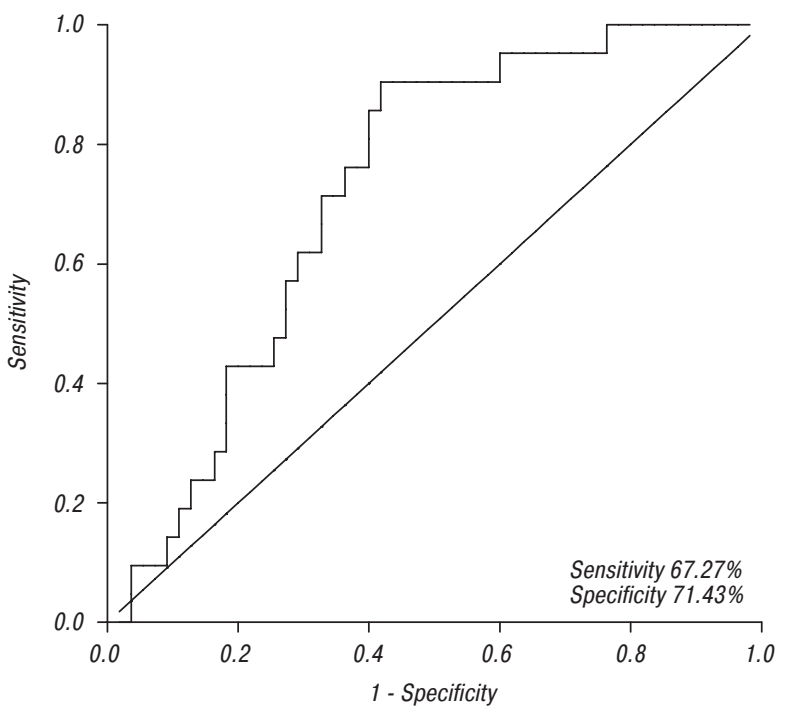

(c)

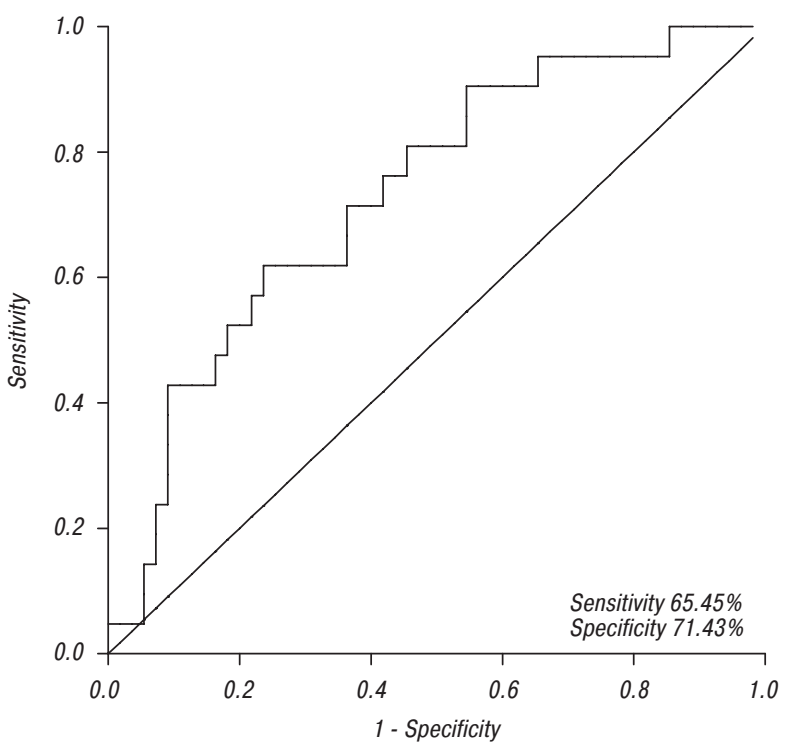

Fig. 8. Diagnostic potential of anti-TF antibody ratios and SNA/ IgG index in patients with early (stage I) colon cancer as evaluated by the receiver operator characteristic curve analysis: $a-\lg \mathrm{G} / \operatorname{lgM} ; b-\lg \mathrm{G} / \lg \mathrm{A} ; c-\mathrm{SNA} / \lg \mathrm{G}$ index survival was quite opposite in early and advanced cancer (Fig. 9, $f, g$ ).

We recently showed that the SNA-reactivity of antiTF antibodies in patients with gastric cancer, irrespective of the disease stage, was significantly higher [29]. In the present study, a similar increase in antibodies sialylation was found only in stage III-IV colon cancer patients (see Fig. 5) and these changes were associated mostly with the level of IgG antibodies. Notably, in contrast to SNA binding to a pool of all anti-TF antibody isotypes, the significantly higher SNA/lgG index was observed independently of cancer stage. Besides, a close association of the increased SNA reactivity of anti-TF antibodies with their lower avidity was detected (Fig. 7).

An increased level of alpha2,6-sialylation of serum glycoproteins, often observed in tumor cells, protects them from humoral and cellular immunity, acting as an antirecognition agent and contributing to cells being "self", thus increasing the metastatic potential of tumor cells [1, 5, 43-45]. It has been shown that the SNA lectin binds preferentially glycans terminated with alpha-2,6 sialic acid on the Fab fragments of IgG [46] and about $1 \%$ of IgG Fc binds the lectin only when two sialic acids are present $[47,48]$. We speculate that the increased expression of sialyltransferases frequently observed in cancer cells [49] would lead to hypersialylation in the Fab region of TF-specific antibodies in situ that may interfere with the antigen antibody interplay, thus influencing the antibody avidity. In fact, the decreased avidity of TF-specific antibodies in cancer was mostly associated with the SNA-reactive antibodies and was observed already at a very early stage of cancer (see Fig. 7). Our data about the increased sialylation of anti-TF antibodies in patients with advanced colon cancer, as well as the lower avidity of SNA-reactive antibodies and the stageand antibody isotype-dependent association of the IgG sialylation index with survival suggest that the TFspecific antibody sialylation should strongly influence the anti-tumor immunity and may be a promising target for cancer immunotherapy.

Another significant finding was that the impact of antibodies sialylation profile, as evaluated by the SNA/Ig index, on survival may be quite different at various stages of cancer (Fig. 9, $i, j$ ). A similar stage-dependency was observed with $\mathrm{IgG} / \mathrm{IgM}$ ratio (Fig. 9, $f, g$ ), indicating that survival analysis should be performed in a stage-dependent manner, otherwise its association with survival or diagnostic potential may be hidden by the above stage-related discrepancies.

Given the responsibility of sialylated IgG antibodies for anti-inflammatory effects of intravenous immunoglobulins [34, 51, 52], we suggest that the association of a higher SNA/lgG index with a benefit in survival (Fig. 9, i) should be related to the inhibition of in situ inflammatory reactions, which is known to promote tumor growth $[50,53]$. Alternatively, it may be speculated that higher sialylated TF-specific antibodies would 

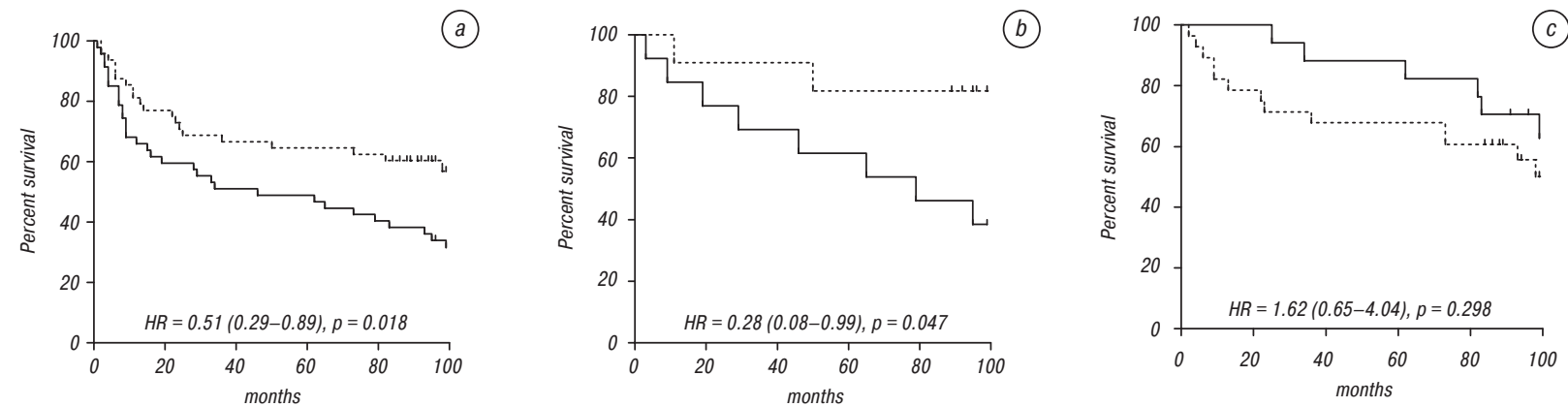

(d)
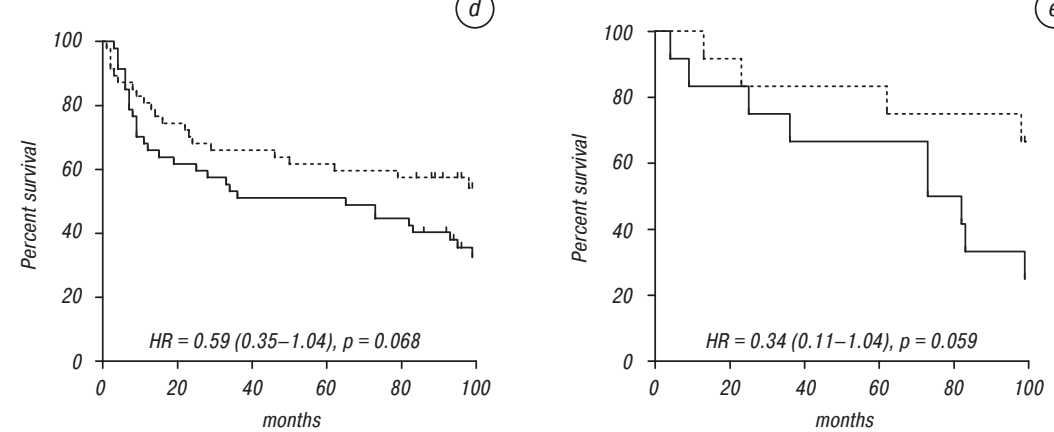

(f)
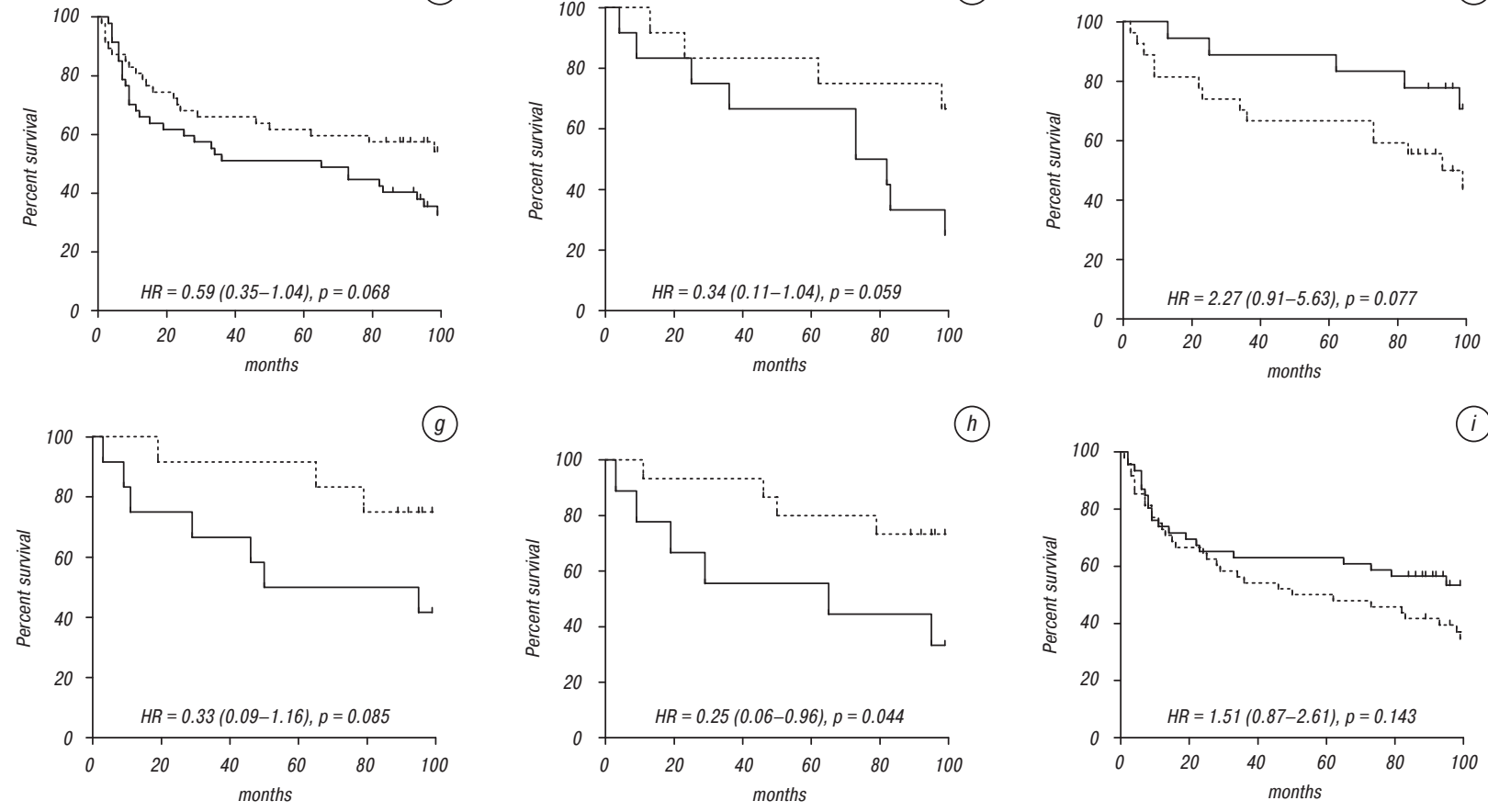

(b)
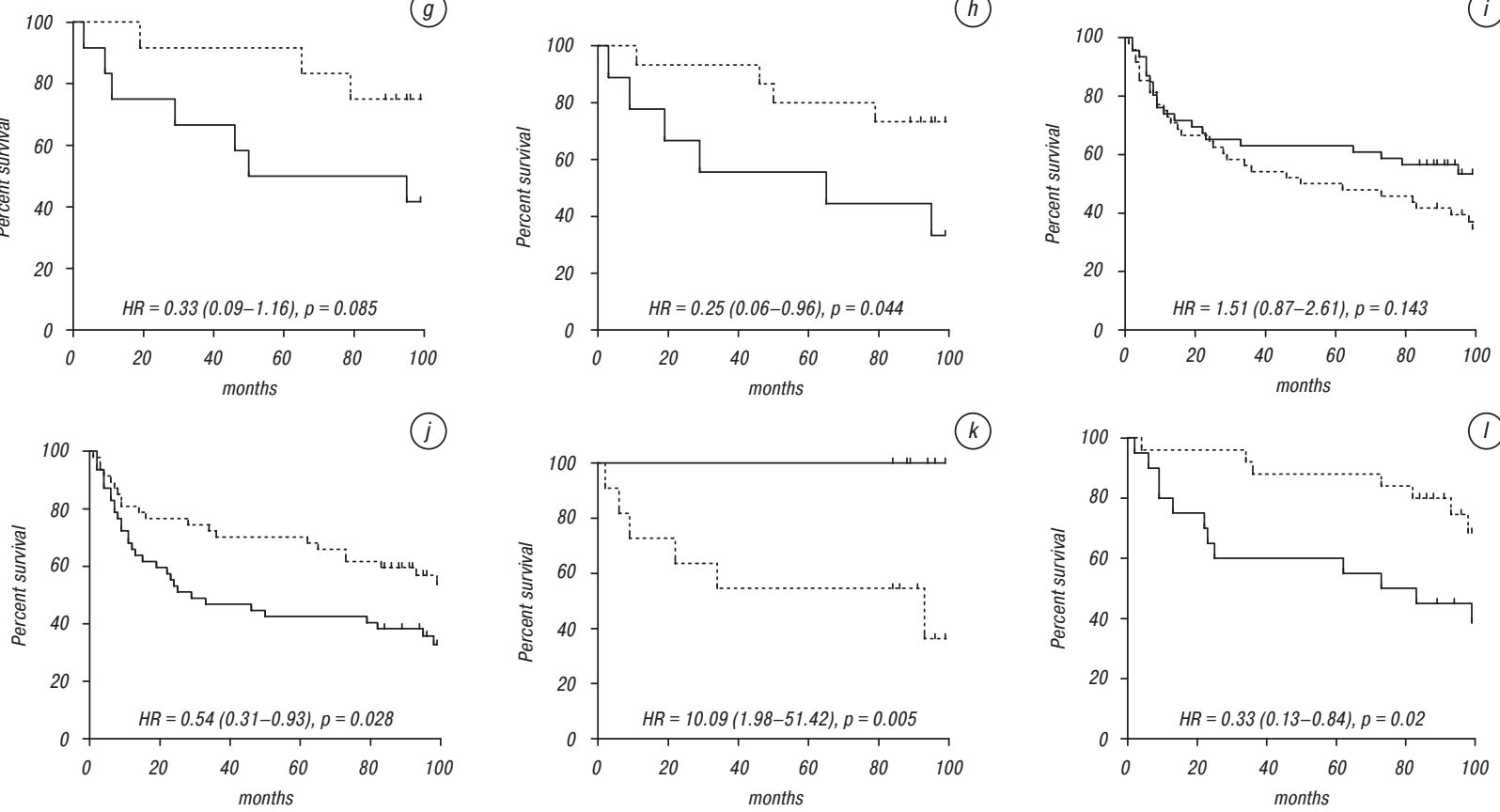

Fig. 9. The probability of survival of cancer patients in relation to the level of anti-TF antibody isotypes, their relative proportions and SNA reactivity: $a-$ anti-TF Ab level (a pool of all isotypes), all patients $(n=95) ; b-$ anti-TF Ab level (a pool of all isotypes), stage III patients $(\mathrm{n}=24) ; \mathrm{c}-$ anti-TF IgG level, stage I + II $(\mathrm{n}=45) ; d-$ anti-TF IgA level, all patients $(\mathrm{n}=94) ; e-$ anti-TF IgA level, stage II $(\mathrm{n}=24) ; f$ - anti-TF IgG/IgM ratio, stage I + II $(\mathrm{n}=45) ; g-$ anti-TF IgG/IgM ratio, stage III $(\mathrm{n}=24) ; h-$ anti-TF IgA/ IgM ratio, stage III $(\mathrm{n}=24) ; i-\mathrm{SNA} /$ anti-TF IgG index, all patients $(\mathrm{n}=94) ; j-\mathrm{SNA} / \mathrm{IgM}$ index, all stages $(\mathrm{n}=94) ; k-$ IgM avidity index, stage I $(n=22) ; I$ - avidity of SNA-reactive anti-TF antibodies, stage I + II $(n=45)$. Patients having values lower than, equal to (a dashed line) or higher than median (a solid line) were subjected to study using the Kaplan - Meier method. The hazard ratio (HR) with a 95\% confidence interval and $p$-values are shown

act as blocking or interfering antibodies, as has been shown, for instance, for an increased sialylation of lgG against embryonic antigens, which protects the fetus in pregnancy [54].

The currently dominating approach in anti-glycan antibody studies on cancer patients is the antibody levels profiling. The analysis employs multi-glycan microarray techniques $[35,55,56]$ to find cancerspecific changes based on antibody profiling and/ or multiplex combination of more informative antibodies. However, given the extremely high structural and functional polymorphism of anti-glycan antibodies, we believe that a more promising approach might be a search for disease-specific antibody subsets. The latter may represent only a small subpopulation of the whole anti-glycan antibodies pool (to a given $\mathrm{Ag}$ ) where such subsets will be masked by dominant antibodies which show no cancer-related changes. 
Table 2. The diagnostic sensitivity, specificity and accuracy for representative parameters studied, at different stages of cancer.

\begin{tabular}{|c|c|c|c|c|c|c|c|c|c|}
\hline Parameter & Stage & Sensitivity, \% & $95 \% \mathrm{Cl}$ & Specificity, \% & $95 \% \mathrm{Cl}$ & $p$-value & $95 \% \mathrm{Cl}$ & ACC & $\begin{array}{c}\text { Sensitivity at } 90 \% \\
\text { Specificity }\end{array}$ \\
\hline IgG/lgM ratio & I & 69.84 & $0.57-0.81$ & 76.19 & $0.65-0.85$ & 0.0005 & $0.53-0.92$ & 0.71 & 60.32 \\
\hline IgG/lgM ratio & I-II & 71.43 & $0.59-0.82$ & 57.78 & $0.57-0.77$ & 0.0022 & $0.42-0.72$ & 0.66 & 26.98 \\
\hline IgG/lgM ratio & III-IV & 60.32 & $0.47-0.72$ & 65.31 & $0.49-0.70$ & 0.0618 & $0.50-0.78$ & 0.63 & 17.46 \\
\hline IgM level & I & 60.94 & $0.48-0.73$ & 52.38 & $0.40-0.70$ & 0.4789 & $0.30-0.74$ & 0.41 & 14.06 \\
\hline IgM level & III-IV & 62.5 & $0.50-0.74$ & 46.94 & $0.46-0.67$ & 0.2226 & $0.33-0.62$ & 0.44 & 12.50 \\
\hline $\lg G / \lg A$ ratio & I & 67.27 & $0.53-0.79$ & 71.43 & $0.61-0.84$ & 0.0027 & $0.48-0.89$ & 0.68 & 58.18 \\
\hline IgG/lgA ratio & $1-11$ & 63.64 & $0.50-0.76$ & 64.44 & $0.58-0.79$ & 0.0018 & $0.49-0.78$ & 0.64 & 40.00 \\
\hline SNA/IgG Index & 1 & 65.45 & $0.51-0.78$ & 71.43 & $0.62-0.86$ & 0.0013 & $0.48-0.89$ & 0.67 & 47.27 \\
\hline SNA/IgG Index & $|-| \mid$ & 65.45 & $0.51-0.78$ & 68.89 & $0.61-0.81$ & 0.0004 & $0.53-0.82$ & 0.67 & 47.27 \\
\hline SNA/IgG Index & III-IV & 65.45 & $0.51-0.78$ & 69.39 & $0.62-0.81$ & 0.0001 & $0.55-0.82$ & 0.67 & 41.64 \\
\hline SNA/IgG Index & I-IV & 65.45 & $0.51-0.78$ & 69.15 & $0.62-0.80$ & $<0.0001$ & $0.59-0.78$ & 0.68 & 41.82 \\
\hline SNA/IgA Index & I & 49.09 & $0.35-0.63$ & 66.67 & $0.40-0.69$ & 0.5381 & $0.43-0.85$ & 0.54 & 12.91 \\
\hline SNA/IgA Index & I-II & 47.27 & $0.34-0.61$ & 71.11 & $0.43-0.66$ & 0.4754 & $0.56-0.84$ & 0.58 & 14.55 \\
\hline SNA/lgA Index & III-IV & 50.91 & $0.37-0.65$ & 73.47 & $0.52-0.74$ & 0.0242 & $0.59-0.85$ & 0.62 & 27.09 \\
\hline Avidity of SNA + antibody & I-IV & 65.63 & $0.47-0.81$ & 64.21 & $0.52-0.77$ & 0.0148 & $0.54-0.74$ & 0.65 & 25.00 \\
\hline Avidity of SNA + antibody & $|-1|$ & 65.63 & $0.47-0.81$ & 63.04 & $0.52-0.78$ & 0.0275 & $0.48-0.77$ & 0.64 & 34.38 \\
\hline Avidity of SNA + antibody & III-IV & 65.63 & $0.47-0.81$ & 65.31 & $0.51-0.78$ & 0.032 & $0.50-0.78$ & 0.65 & 21.88 \\
\hline
\end{tabular}

Note: The area under the curve (AUC) with 95\% confidence interval (CI), the accuracy of diagnostics (ACC) and $p$-values are presented.

This diversity may also explain the rather variable and often quite opposite effects of glycan-targeted immunotherapeutic attempts [10].

In conclusion, patients with colon cancer displayed a higher level of anti-TF-IgM antibodies, a lower TF-specific IgG/IgM and IgG/IgA ratios, and an increased SNA reactivity of anti-TF antibodies at the advanced stages of the disease mostly on account of IgG, and a lower avidity of TF-specific antibodies, especially their SNA-reactive subset. The higher sialylation of TF specific antibodies in colon carcinoma found in this study is in agreement with our previous data obtained about patients with gastric or breast cancer (manuscript in preparation) in which these changes were even more pronounced. Thus it appears that the hypersialylation of TF-specific antibodies is a common phenomenon in cancer. To our knowledge, no analyses of the distribution, avidity and sialylation pattern of anti-TF antibody isotypes have been performed before for anti-tumorassociated glycans antibodies in colon cancer and these signatures seem to be clinically more promising diagnostic and prognostic parameters than just the level of antibodies per se.

In summary, we report for the first time on the diversity of anti-TF humoral immune response in patients with colon cancer, which shows the diagnostic and prognostic potential. It is important to note that some of the cancer-related changes occur in colon cancer patients already at the early stage of the disease, thus making these changes promising serological biomarkers for early cancer diagnostics and screening. Given there are still no reliable antibody-based biomarkers for early colon cancer $[35,36]$, our data on the structural and functional diversity of TF-specific antibodies merit further study to validate naturally occurring anti-glycan antibody signatures in a large prospective population in several independent cohorts to further decipher the role of anti-glycan antibodies in cancer.

\section{CONFLICT OF INTERESTS}

The author declare that there is no conflict of interests regarding the publication of this paper.

\section{ACKNOWLEDGEMENTS}

This work was supported by the Estonian Research Council Grant PUT371.

\section{REFERENCES}

1. Hakomori S. Aberrant glycosylation in tumors and tumor-associated carbohydrate antigens. Advances Cancer Res 1989; 52; 257-331.

2. Hakomori S. Glycosylation defining cancer malignancy: new wine in an old bottle. Proc Natl Acad Sci USA 2002; 99: 10231-3.

3. Kailemi MJ, Park D, Lebrilla CB. Glycans and glycoproteins as specific biomarkers for cancer. Anal Bioanal Chem 2017; 409: 395-410.

4. Ohtsubo K, Marth JD. Glycosylation in cellular mechanisms of health and disease. Cell 2006; 126: 855-67.

5. Hakomori SI, Cummings RD. Glycosylation effects on cancer development. Glycoconjugate J 2012; 29: 565-6.

6. Kudelka MR, Ju T, Heimburg-Molinaro J, et al. Simple sugars to complex disease-mucin-type O-glycans in cancer. Adv Cancer Res 2015; 126: 53-135.

7. Desai PR. Immunoreactive $T$ and $T n$ antigens in malignancy: role in carcinoma diagnosis, prognosis, and immunotherapy. Transfusion Med Rev 2000; 14: 312-25.

8. Baldus SE, Zirbes TK, Hanisch FG, et al. Thomsen Friedenreich antigen presents as a prognostic factor in colorectal carcinoma: A clinicopathologic study of 264 patients. Cancer 2000; 88: 1536-43.

9. Yu LG. The oncofetal Thomsen - Friedenreich carbohydrate antigen in cancer progressioon. Glycoconj J 2007; 24: 411-20.

10. Monzavi-Karbassi B, Pashov A, Kieber-Emmons T. Tumor-associated glycans and immune surveillance. Vaccines (Basel) 2013; 1: 174-203.

11. Radhakrishnan $P$, Dabelsteen $S$, Madsen FB, et al. Immature truncated O-glycophenotype of cancer directly induces oncogenic features. Proc Natl Acad Sci U S A 2014; 111: E4066-75.

12. Springer GF. Immunoreactive $T$ and $T n$ epitopes in cancer diagnosis, prognosis and immunotherapy. J Mol Med 1997; 75: 594-602.

13. Kurtenkov O, Miljukhina L, Smorodin J, et al. Natural IgM and IgG antibodies to Thomsen - Friedenreich (T) antigen in serum of patients with gastric cancer and blood donors. Acta Oncol 1999; 38: 939-43.

14. Almogren J, Abdullah $K$, Ghapure $K$, et al. AntiThomsen - Friedenreich-Ag (anti-TF-Ag) potential for cancer therapy. Front Biosci 2012; 4: 840-63. 
15. Inamdar SR, Azharuddin M, Savanur MA, et al. The TF-antigen binding lectin from Sclerotium rolfsii inhibits growth of human colon cancer cells by inducing apoptosis in vitro and suppresses tumor growth in vivo. Glycobiology 2012; 22: 1227-35.

16. Yi B, Zhang M, Schwartz-Albiez, Cao Y. Mechanisms of the apoptosis induced by CD176 antibody in human leukemic cells. Int J Oncol 2011; 38: 1565-73.

17. Springer GF, Desai PR, Spencer BD, et al. T/Tn antigen vaccine is effective and safe in preventing recurrence of advanced breast carcinoma. Cancer Detect Prevent 1995; 19: $374-80$.

18. Kurtenkov O, Klaamas $\mathrm{K}$, Rittenhouse-Olson $\mathrm{K}$, et al. IgG immune response to tumor-associated carbohydrate antigens (TF, Tn, alphaGal) in patients with breast cancer: impact of neoadjuvant chemotherapy and relation to the survival. Exp Oncol 2005; 27: 136-40.

19. Kurtenkov O, Klaamas K, von Mensdorff-Pouilly S, et al. Humoral immune response to MUC1 and tumor-related glycotopes (Gal beta1-3GalNAc, Gal alpha1-3Gal) in patients with gastric cancer and benign gastric diseases: relation to survival. Acta Oncologica 2007; 46: 316-23.

20. Smorodin EP, Sergeyev BL, Klaamas KV, et al. The relation of the level of serum anti-TF, -Tn and-alpha-Gal IgG to survival in gastrointestinal cancer patients. Int $\mathrm{J}$ Med Sci 2013; 10: 1674-82.

21. Heimburg J, Yan J, Morey S, et al. Inhibition of spontaneous breast cancer metastasis by anti-Thomsen - Friedenreich antigenmonoclonal antibody JAA-F11. Neoplasia 2006; 8: 939-48.

22. Ferguson K, Yadav A, Morey S, et al. Preclinical studies with JAA-F11 anti-Thomsen - Friedenreich monoclonal antibody for human breast cancer. Future Oncol 2014; 10: 385-99.

23. Kodar K, Stadlmann J, Klaamas K, et al. Immunoglobulin $\mathrm{G} \mathrm{Fc} \mathrm{N-glycan} \mathrm{profiling} \mathrm{in} \mathrm{patients} \mathrm{with} \mathrm{gastric} \mathrm{cancer}$ by LC-ESI-MS: relation to tumor progression and survival. Glycoconj J 2012; 29: 57-66.

24. Ren S, Zhang Z, Xu C, et al. Distribution of IgG galactosylation as a promising biomarker fro cancer screening in multiple cancer types. Cell Res 2016; 26: 963-6.

25. Evropi T, K. Thaçi T, Agakov F, et al. Glycosylation of plasma IgG in colorectal cancer prognosis. Sci Rep 2016: Art number: 28098.

26. Mehta S, Long RE, Comunale MA, et al. Increased levels of galactose-deficient anti-Gal immunoglobulin $\mathrm{G}$ in the sera of hepatitis $\mathrm{C}$ virus-infected individuals with fibrosis and cirrhosis. J Virol 2008; 82: 1259-70.

27. Kodar K, Kurtenkov O, Klaamas K. The Thomsen Friedenreich antigen and alphaGal-specific human IgG glycoforms: concanavalin A reactivity and relation to survival of cancer patients. Immunol Invest 2009; 38: 704-17.

28. Kodar K, Izotova J, Klaamas K, et al. Aberrant glycosylation of the anti-Thomsen - Friedenreich glycotope IgG in gastric cancer patients. World J Gastroenterol 2013; 19: $3573-82$.

29. Kurtenkov O, Izotova J, Klaamas K, et al. Increased sialylation of anti-Thomsen - Friedenreich antigen (CD176) antibodies in patients with gastric cancer: a diagnostic and prognostic potential. Biomed Res Int 2014: 830847. Doi: $10.1155 / 2014 / 830847$.

30. Kurtenkov O, Klaamas K. Increased avidity of the Sambucus nigra lectin-reactive antibodies to the Thomsen Friedenreich antigen as a potential biomarker for gastric cancer. Dis Markers 2015: doi:1155/2015/761908.

31. Ferlay J, Soerjomataram I, Dikshit R, et al. Cancer incidence and mortality worldwide: sources, methods and major patterns in GLOBOCAN 2012. Int J Cancer 2015; 136: E359-86.

32. Hundt S, Haug U, Brenner H. Blood markers for early detection of colorectal cancer: a systematic review. Cancer Epidemiol Biomarkers Prev 2007; 16: 1935-53.

33. Wandall HH, Blixt O, Tarp MA, et al. Cancer biomarkers defined by autoantibody signatures to aberrant Oglycopeptide epitopes. Cancer Res 2010; 70: 1306-13.

34. Oaks M, Taylor S, Shaffer J. Autoantibodies targetting tumor-associated antigens in metastatic cancer. Sialylated IgGs as candidate anti-inlfammatory antibodies. Oncoimmunology 2013; 2: e2481.

35. Chen H, Werner S, Butt J, et al. Prospective evaluation of 64 serum autoantibodies as biomarkers for early detection of colorectal cancer in a true screening setting. Oncotarget 2016; 7: 16420-32.

36. Werner S, Chen H, Butt J, et al. Evaluation of the diagnostic value of 64 simultaneously measured autoantibodies for early detection of gastric cancer. Scientific Rep 2016; 6: 25467.

37. Dube DH, Bertozzi CR. Glycans in cancer and inflammation - potential for therapeutics and diagnostics. Nat Rev Drug Discov 2005; 4: 477-88.

38. Rabinovich GA, Croci DO. Regulatory circuits mediated by lectin-glycan interactions in autoimmunity and cancer. Immunity 2012; 36: 322-35.

39. Hayes JM, Wormald MR, Rudd PM, et al. Fc gamma receptors: glycobiology and therapeutic prospects. J Inflamm Res 2016; 9: 209-19.

40. Smorodin EP, Kurtenkov OA, Sergeyev BL, et al. Postoperative change of anti-Thomsen - Friedenreich and Tn IgG level: the followup study of gastrointestinal cancer patients. World J Gastroenterol 2008; 14: 4352-8.

41. Kurtenkov O, Klaamas K, Miljukhina L. The lower level of natural anti-Thomsen - Friedenreich Antigen (TFA) agglutinins in sera of patients with gastric cancer related to $\mathrm{ABO}(\mathrm{H})$ blood-group phenotype. Int J Cancer 1995; 60: 781-5.

42. Smorodin EP, Sergeyev BL. The level of IgG antibodies reactive to TF, Tn and alpha-Gal polyacrylamideglycoconjugates in breast cancer patients: relation to survival. Exp Oncol 2016; 38: 117-21.

43. Alley WR, Novotny MV. Glycomic analysis of sialic acid linkages in glycans derived from blood serum glycoproteins. J Proteome Res 2010; 9: 3062-72.

44. Schauer R. Sialic acids as regulators of molecular and cellular interactions. Curr Opin Struct Biol 2009; 19: $507-14$.

45. Bull C, Stoel MA, den Brok MH, et al. Sialic acids sweeten a tumor's life. Cancer Res 2014; 74: 3199-204.

46. Käsermann F, Boerema DJ, Rüegsegger M, et al. Analysis and functional consequences of increased Fab-sialylation of intravenous immunoglobulin (IVIG) after lectin fractionation. Plos One 2012; 7: e37243.

47. Stadlmann J, Weber A, Pabst M, et al. A close look at human $\mathrm{IgG}$ sialylation and subclass distribution after lectin fractionation. Proteomics 2009; 9: 4143-53.

48. Stadlmann J, Pabs M, Altmann F. Analytical and functional aspects of antibody sialylation. J Clin Immunol 2010; 30 (suppl 1): S15-9.

49. Harduin-Lepers A, Krzewinski-Recchi MA, Colomb F, et al. Sialyltransferases functions in cancers. Front Biosci (Elite Ed) 2012; 4: 499-515.

50. Collin M, Ehlers M. The carbohydrate switch between pathogenic and immunosuppressive antigen-specific antibodies. Exp Dermatol 2013; 2: 511-4. 
51. Böhm S, Schwab I, Lux A, et al. The role of sialic acid as a modulator of the anti-inflammatory activity of IgG. Semin Immunopathol 2012; 34: 443-53.

52. Kaneko Y, Nimmerjahn F, Ravetch JV. Anti-inflammatory activity of immunoglobulin $\mathrm{G}$ resulting from Fc sialyation. Science 2006; 313: 670-3.

53. Tan TT, Coussens LM. Humoral immunity, inflammation and cancer. Curr Opin Immunol, 2007; 19: $209-16$.

54. Van de Geijn FE, Wuhrer M, Selman MH, et al. Immunoglobulin $\mathrm{G}$ galactosylation and sialylation are associated with pregnancy-induced improvement of rheumatoid arthritis and the postpartum flare: results from a large prospective cohort study. Arthritis Res Ther 2009; 11: R193.

55. Schneider C, Smith DF, Cummings MD, et al. The human $\mathrm{IgG}$ anti-carbohydrate repertoire exhibits a universal architecture and contains specificity for microbial attachment sites. Sci Transl Med 2015; 7: 269ra1.

56. Butvilovskaya VI, Popletaeva SB, Chechetkin VR, et al. Multiplex determination of serological signatures in the sera of colorectal cancer patients using hydrogel biochips. Cancer Med 2016; 5: 1361-72. 